\title{
Article \\ Effect of Wood Fiber Surface Treatment on the Properties of Recycled HDPE/Maple Fiber Composites
}

\author{
Roberto C. Vázquez Fletes (D) and Denis Rodrigue *(D) \\ Department of Chemical Engineering, Université Laval, Quebec, QC G1V 0A6, Canada; \\ roberto-carlos.vazquez-fletes.1@ulaval.ca \\ * Correspondence: denis.rodrigue@gch.ulaval.ca; Tel.: +1-418-656-2903
}

Citation: Fletes, R.C.V.; Rodrigue, D. Effect of Wood Fiber Surface

Treatment on the Properties of Recycled HDPE/Maple Fiber Composites. J. Compos. Sci. 2021, 5 , 177. https://doi.org/10.3390/ jes5070177

Academic Editors: Deesy G. Pinto and Virupaxi Auradi

Received: 16 June 2021

Accepted: 5 July 2021

Published: 7 July 2021

Publisher's Note: MDPI stays neutral with regard to jurisdictional claims in published maps and institutional affiliations.

Copyright: (C) 2021 by the authors Licensee MDPI, Basel, Switzerland. This article is an open access article distributed under the terms and conditions of the Creative Commons Attribution (CC BY) license (https:// creativecommons.org/licenses/by/ $4.0 /)$.

\begin{abstract}
This work reports on the production and characterization of recycled high density polyethylene (R-HDPE) composites reinforced with maple fibers. The composites were produced by a simple dry-blending technique followed by compression molding. Furthermore, a fiber surface treatment was performed using a coupling agent (maleated polyethylene, MAPE) in solution. FTIR, TGA/DTG, and density analyses were performed to confirm any changes in the functional groups on the fiber surface, which was confirmed by SEM-EDS. As expected, the composites based on treated fiber (TC) showed improved properties compared to composites based on untreated fiber (UC). In particular, MAPE was shown to substantially improve the polymer-fiber interface quality, thus leading to better mechanical properties in terms of tensile modulus (23\%), flexural modulus (54\%), tensile strength $(26 \%)$, and flexural strength $(46 \%)$ as compared to the neat matrix. The impact resistance also increased by up to $87 \%$ for TC as compared to UC. In addition, the maximum fiber content to produce good parts increased from 15 to $75 \mathrm{wt} \%$ when treated fiber was used. These composites can be seen as sustainable materials and possible alternatives for the development of low-cost building/construction/furniture applications.
\end{abstract}

Keywords: high density polyethylene; maple; composites; recycling; dry blending; compression molding; mechanical properties

\section{Introduction}

Plastic waste is one of the major solid residues today. More than 300 million tons of plastics are produced annually, of which 50\% are single-use plastics (SUP) [1]. In 2010, about 275 million tons of plastic waste were generated, which increased to 5 billion tons in 2015 [2]. Today, it is estimated that this value will increase by 9-13\% by the year 2025 [3]. Unfortunately, most of these plastic wastes are still landfilled, lost in the environment (like ocean plastics), or burned [4]. As our consumption is still rising, there is a greater need to recycle these materials and/or find ways to reduce their use. Therefore, plastic recycling has received considerable attention in recent years [3,5-7].

Plastic recycling has the potential of partially replacing the use of virgin plastics as a source of raw materials in the production of several products. For this reason, it is one of the most common methods for plastic waste management and a good option to better control these wastes [8]. However, the use of $100 \%$ recycled materials is still difficult due to various technical difficulties; in general, there is no exact knowledge of the composition and properties of the materials because they do not come from the same source, which implies that they have differences in molecular weights, transition temperatures, particle sizes, melt index, and even the type of additives or impurities they contain $[3,5]$. Even so, the formulation of composite materials is an interesting option, and the scientific community is focused on the use of virgin [9-13] and recycled [14-20] polymers as matrices for the production of natural fiber/plastic composites (NFPC) in order to reduce the polymer content and find added-value applications for these wastes (plastics and natural fibers) that 
can lead to more sustainable solutions. This combination offers several advantages such as better management of natural resources and a suitable way to eliminate plastic waste. Furthermore, the possibility of using recycled materials in the development of composites is very attractive, especially concerning the large amount of natural fiber/plastic waste that is generated daily [21].

The use of natural fibers (agave, kenaf, henequen, jute, coconut, pine, maple, etc.) in the production of NFPC is considered one of the main sustainable alternatives to composite materials based on synthetic fibers (glass, aramid, carbon, etc.). This is due to natural fibers offering important advantages such as availability, low cost, easier processing, less damage to the processing equipment, lower $\mathrm{CO}_{2}$ emissions, reduction of the energy used during production (up to $80 \%$ ), better recyclability, and environmental safety $[18,22,23]$. Currently, around 30 million tons of natural fibers are used in the production of NFPC for automotive parts, packaging, sports equipment, and most importantly, for building and construction as well as structural applications [10,24,25].

But natural fibers reinforcing polymer matrices also have disadvantages such as high moisture absorption and a weak adhesion between the fibers and the matrix combined with difficult dispersion. Due to their chemical nature, natural fibers are polar and hydrophilic (active water absorption sites), while most polymers are non-polar and hydrophobic. This causes incompatibility between both components that leads to low mechanical properties. Nevertheless, mechanical/physical properties can be improved by using a suitable compatibilizer/coupling agent and/or by performing fiber surface treatment (chemical, mechanical, physical, or thermal) [23]. This modification can improve both the fiber adhesion and dispersion, leading to better NFPC performances [22,26].

In a recent publication, it was shown that the use of maleated polyethylene (MAPE) in solution improves fiber-matrix interactions, mainly in terms of the adhesion and dispersion of maple fiber in linear low-density polyethylene (LLDPE) composites [23]. For example, Cisneros-López et al. [26] showed that by adding MAPE in solution, the mechanical properties of agave fiber/LLDPE-tensile modulus (70\%), flexural modulus (164\%), tensile strength $(29 \%)$, and flexural strength $(121 \%)$-were improved as compared to the neat matrix.

The possible amount of fiber in the NFPC was increased up to $80 \%$, leading to higher tensile modulus (101\%), flexural modulus (129\%), and tensile strength (50\%) compared to samples without MAPE. Raharjo et al. [27] also reported improved interfacial adhesion, resistance to shear, and thermal stability by using chemical treatments (alkali, silane) on agave cantala fibers with recycled high-density polyethylene (R-HDPE). Lei et al. [19] obtained similar results in NFPC produced by extrusion, followed by compression molding using sugar cane bagasse and pine fibers with R-HDPE and subsequently adding MAPE as a compatibilizer, which improved the interaction between both components that led to better tensile modulus, tensile strength, and impact resistance as compared to the NFPC without MAPE. In another study, Sataphaty developed NFPC from industrial and post-consumer waste: R-HDPE and jute fiber with MAPE [28]. It was observed that the tensile strength and modulus, the flexural strength and modulus, as well as the hardness significantly increased with $20 \mathrm{wt} \%$ of fiber. In addition, the author suggested that these materials have a high potential for roofing and furniture applications.

Due to the limited amount of information on the use of recycled polymers as matrices, the main objective of this work is to produce and characterize NFPC based on a post-consumer recycled matrix. To do so, recycled high-density polyethylene (R-HDPE) composites reinforced with a hardwood residue (maple fiber) with different concentrations $(0,15,30,45,60$, and $75 \mathrm{wt} \%)$ were produced with and without MAPE. To limit polymer degradation and reduce processing time, a simple dry-blending technique was followed by compression molding to develop a low-cost and added-value NFPC from more environmentally sustainable materials. Additionally, a sample based on $100 \%$ treated fibers is presented for comparison and to open the door for future optimization. 


\section{Materials and Methods}

\subsection{Materials}

In this work, recycled high-density polyethylene (R-HDPE) was used as the matrix and supplied by Service de Consultation Sinclair (Drummondville, QC, Canada) in flakes that came from recycled solid HDPE bottles. R-HDPE was first pulverized with a Lab Mill model PKA-18 (Powder King, Phoenix, AZ, USA) and then sieved to keep a size between 1 and $3 \mathrm{~mm}$ (Figure 1a). Then, the R-HDPE powder was characterized to obtain its melt flow index $\left(6.7 \mathrm{~g} / 10 \mathrm{~min}\right.$ at $\left.2.16 \mathrm{~kg}, 190^{\circ} \mathrm{C}\right)$ and melting temperature $\left(123^{\circ} \mathrm{C}\right)$ [29]. As reinforcement, maple wood fibers from PWI Industries (St-Hyacinthe, QC, Canada) were sieved to keep only fibers between 355 and $500 \mu \mathrm{m}$ (Figure 1b). This is the average fiber size that produces the best dispersion, distribution, and mechanical performance, according to previous studies $[13,30]$.

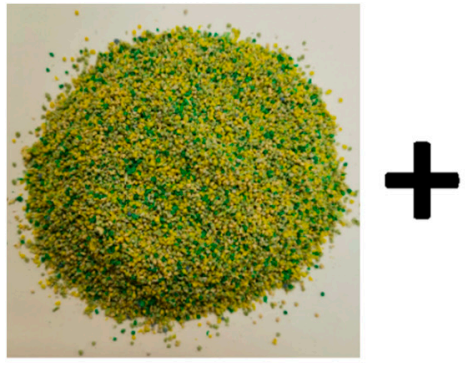

(a)

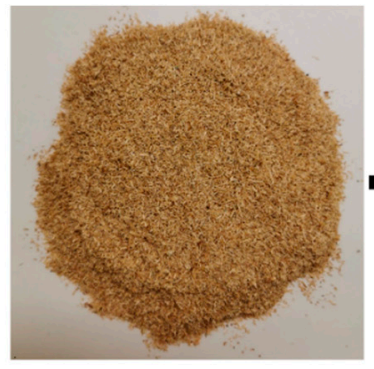

(b)

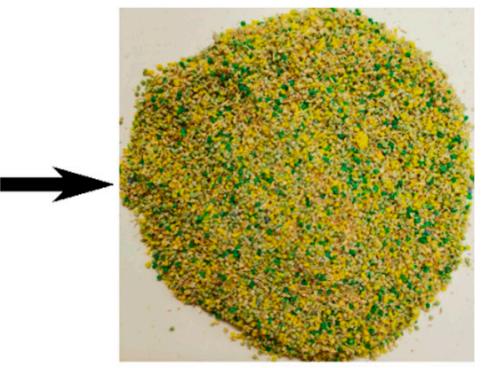

(c)

Figure 1. Raw materials used: (a) Recycled high density polyethylene, (b) maple wood fiber, and (c) a dry blend of the materials.

For the fiber surface treatment, xylene (laboratory purity grade) from Fisher Chemicals (Pittsburgh, PA, USA) and maleic anhydride grafted polyethylene (MAPE) Epolene C-26 from Westlake Chemicals (Houston, TX, USA) were used as received.

\subsection{Fiber Surface Treatment and Composite Preparation}

For surface treatment, $1 \mathrm{wt} \%$ of MAPE was dissolved in xylene at $90{ }^{\circ} \mathrm{C}$ under stirring. Then, $10 \mathrm{wt} \%$ of maple fibers were added to the solution. The treatment was performed for $30 \mathrm{~min}$ at $90{ }^{\circ} \mathrm{C}$ under high intensity mixing. Finally, the fibers were recovered by filtration and dried at $80{ }^{\circ} \mathrm{C}$ in an oven to remove the solvent. More information can be found in Cisneros-López et al. [26]. The composites were prepared by dry blending of untreated (UF) or treated (TF) maple fibers and R-HDPE (Figure 1c). Different fiber contents were used between 0 and $75 \mathrm{wt} \%$ in order to study the effect of this parameter on the quality and properties of the composites. Before processing, the UF and TF were dried overnight at $80^{\circ} \mathrm{C}$ to remove moisture. To get a homogeneous blend, each formulation was mixed with the use of a simple dry-blending technique using a Toastmaster TM-61MC (Smithville, Atlantic County, NJ, USA) blender for $3 \mathrm{~min}$, with a power of $35 \mathrm{~W}$. Finally, $29 \mathrm{~g}$ of each formulation based on untreated fiber (UC) and treated fiber (TC) were placed in a picture frame stainless steel mold with dimensions of $115 \times 115 \times 3 \mathrm{~mm}^{3}$. Compression molding was performed on a laboratory scale press (Carver Inc., Wabash, IN, USA) using the following sequence: preheating for $3 \mathrm{~min}$ at $150{ }^{\circ} \mathrm{C}$, pressing for $5 \mathrm{~min}$ under a load of 3 tons, and cooling down under pressure to $60{ }^{\circ} \mathrm{C}$ using circulating water. The plates were later cut into different geometries for mechanical characterization, as described below. Figure 2 presents a general overview of the NFPC production steps. 


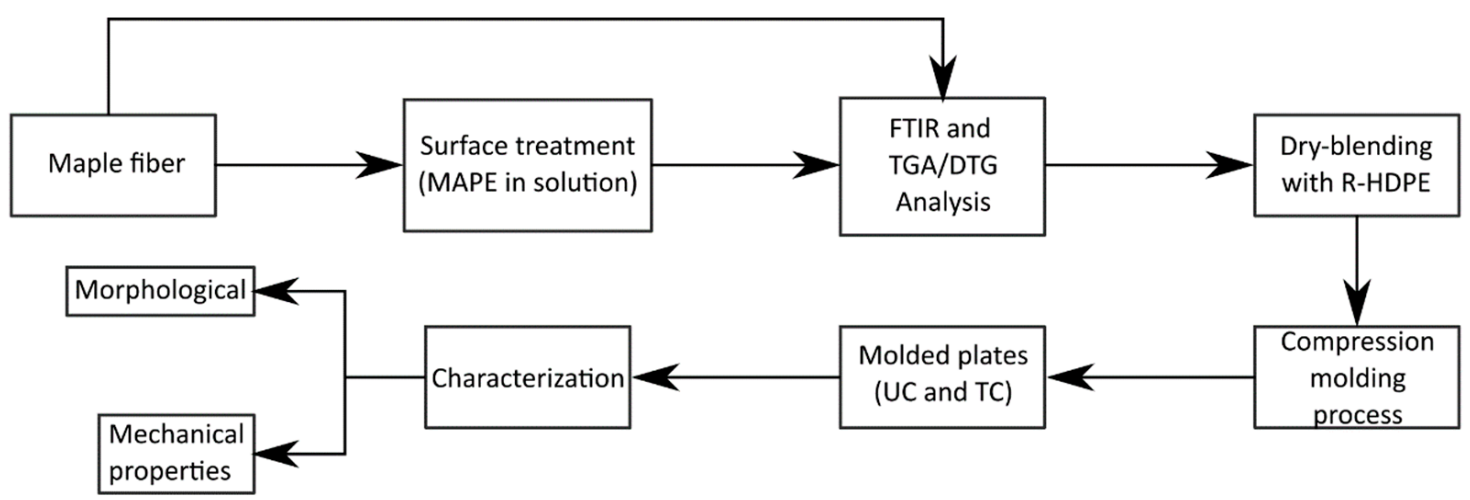

Figure 2. Schematic representation of the processing sequence to produce untreated (UC) and treated fiber (TC) composites with their characterization.

\subsection{Characterization}

\subsubsection{Fourier Transform Infrared Spectroscopy (FTIR)}

To confirm any change in functional groups over the fiber surface from the MAPE solution treatment, Fourier transform infrared spectroscopy (FTIR) spectra were recorded using a Nicolet iS50 FTIR spectrometer from Thermo Scientific (Waltham, MA, USA), equipped with a liquid nitrogen-cooled narrowband MCT detector using Golden Gate (diamond IRE), with an attenuated total reflectance (ATR) accessory from Specac Ltd. (Orpington, UK). Each spectrum was obtained from 128 scans at a resolution of $4 \mathrm{~cm}^{-1}$ from 4000 to $650 \mathrm{~cm}^{-1}$, using Happ-Genzel apodization. All spectral operations were performed using the GRAMS/AI 8.0 software Thermo Galactic (Waltham, MA, USA).

\subsubsection{Thermogravimetric Analysis (TGA)}

Thermogravimetric analysis (TGA) and their derivatives (DTG) were analyzed to evaluate the thermal stability of the neat materials (UF, TF, R-HDPE, MAPE). The tests were performed using a TGA analyzer Q5000IR from TA Instruments (New Castle, DE, USA). Samples between 10 and $20 \mathrm{mg}$ were heated at $10{ }^{\circ} \mathrm{C} / \mathrm{min}$, from 50 to $800{ }^{\circ} \mathrm{C}$, under a nitrogen atmosphere.

\subsubsection{Morphology}

The composites (UC and TC) were cryogenically fractured (liquid nitrogen) and their exposed cross-sections were coated with $\mathrm{Au} / \mathrm{Pd}$ under vacuum. Then, micrographs were taken using a scanning electron microscope (SEM) FEI Inspect (Hillsboro, OR, USA) model F50 at different magnifications to observe the microstructure of samples as well as the state of fiber adhesion/dispersion in the matrix and fiber surfaces. Images of the neat materials were also taken. Additionally, untreated and treated maple fibers were also observed by energy dispersive spectroscopy (EDS) using the same device to verify the surface treatment performed.

\subsubsection{Density/Hardness}

Density was measured with a gas pycnometer, ULTRA-PYC 1200e (Quantachrome Instruments, Boyton Beach, FL, USA), using nitrogen. The results reported are the average of three measurements. Hardness was determined with a durometer, PTC (Los Angeles, CA, USA) model 307L, according to the Shore D scale (thermoplastics), following ASTM D2240. The data reported are the average of a minimum of ten measurements.

\subsubsection{Mechanical Properties}

Tensile and flexural properties were measured on a universal testing machine, Instron 5565 (Instron, Norwood, MA, USA), with a 500 N load cell. For tension, type V dog- 
bone samples were cut from the molded parts, according to ASTM D638. The tests were performed at room temperature and a crosshead speed of $5 \mathrm{~mm} / \mathrm{min}$. The modulus, strength, and elongation at break were reported based on the average of five samples. For flexion, three-point bending tests were performed, according to ASTM D790 at room temperature, using a crosshead speed of $2 \mathrm{~mm} / \mathrm{min}$ and a span length of $60 \mathrm{~mm}$. Five rectangular bars with dimensions of $80 \times 12.7 \times 3 \mathrm{~mm}^{3}$ were tested to report the average and standard deviation for modulus and strength.

Charpy impact strength was determined via a Tinius Olsen (Horsham, PA, USA), model 104 impact tester, with a pendulum of $242 \mathrm{~g}$ (1.22 J). Samples with dimensions of $80 \times 12.7 \times 3 \mathrm{~mm}^{3}$ were used. All the samples were notched in the center of the longitudinal side by an automatic sample notcher, model ASN (Dynisco, Franklin, MA, USA), according to ASTM D6110. The values reported represent the average of ten repetitions.

\section{Results and Discussion}

\subsection{Fourier Transform Infrared Spectroscopy (FTIR)}

Figure 3 presents the FTIR spectra of the untreated (UF) and treated (TF) fibers, as well as MAPE. The UF spectrum shows the typical signals of lignocellulosic fibers: an absorption band associated with hydroxyl groups $(-\mathrm{OH})$ at $3337 \mathrm{~cm}^{-1}$ and a peak at $2893 \mathrm{~cm}^{-1}$, typical of $\mathrm{C}-\mathrm{H}$ bonds, both associated with cellulose and hemicellulose. The peak at $1735 \mathrm{~cm}^{-1}$ corresponds to carbonyl groups $(-\mathrm{C}=\mathrm{O})$ of lignin, hemicellulose, waxes, and pectins. In addition, the peaks at 1594 and $1505 \mathrm{~cm}^{-1}$ are associated with the aromatic structure $(-\mathrm{C}=\mathrm{C}-)$ of lignin, while the $-\mathrm{C}-\mathrm{O}$ bonds of cellulose and lignin are observed at around $1024 \mathrm{~cm}^{-1}$ [31]. In the TF spectrum, a decrease in the band associated with the hydroxyl group was observed, while a slight decrease also occurred at the $1024 \mathrm{~cm}^{-1}$ peak (-C-O). Similarly, a decrease in the peaks is observed at 1594 and $1505 \mathrm{~cm}^{-1}$, indicating the elimination of waxes and pectins during the solution treatment [13]. Finally, two peaks between 2918 and $2848 \mathrm{~cm}^{-1}$, which are characteristics of the alkane groups of the polyethylene chains in MAPE [23], clearly increased. This indicates that MAPE was successfully grafted onto the TF surface. The presence of MAPE chains on the fiber surface is expected to improve the R-HDPE/maple fiber interfacial interaction in the composites. This can be clearly seen in the mechanical properties and the maximum amount of fiber that can be incorporated into a sample, as shown in the next sections.

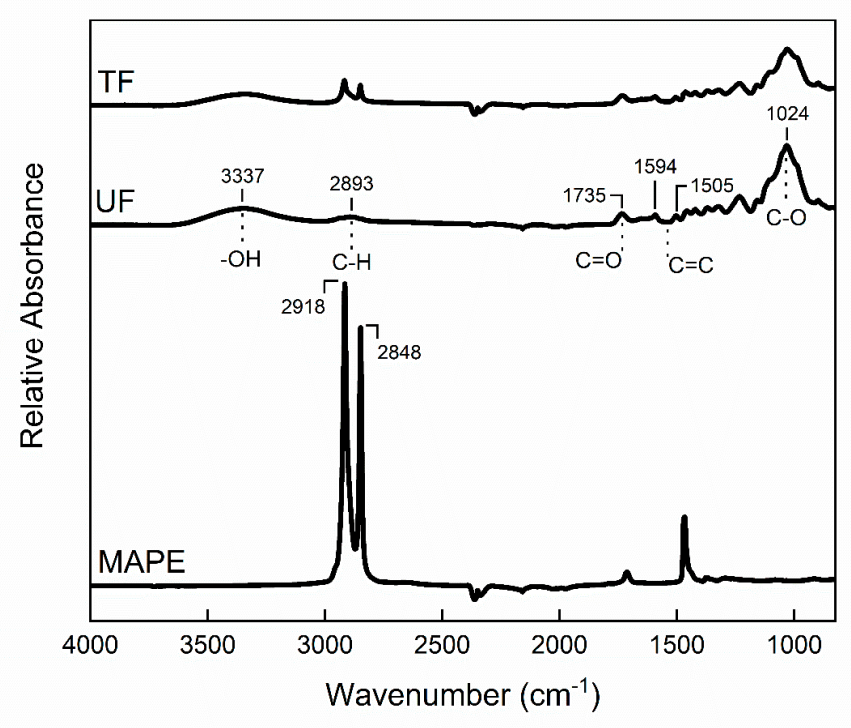

Figure 3. Fourier transform infrared (FTIR) spectra for maleated polyethylene (MAPE), as well as untreated (UF) and treated (TF) maple fibers. 


\subsection{Thermogravimetric Analysis (TGA)}

Thermogravimetric analysis (TGA) was performed to follow the weight curves and their derivatives (DTG) for the neat materials; the results under nitrogen are presented in Figure 4. The weight loss of R-HDPE started at around $390{ }^{\circ} \mathrm{C}$, and nearly $100 \mathrm{wt} \%$ decomposition occurred by $480^{\circ} \mathrm{C}$. In the case of neat MAPE, the thermal behavior is very similar to R-HDPE. On the other hand, the UF and TF curves are different. About $5 \%$ of initial weight loss corresponds to water and other volatile compounds (dehydration) [32]. Subsequently, the main weight loss in the $230-390{ }^{\circ} \mathrm{C}$ range corresponds to the thermal degradation of the fibers [33]. This weight loss is 86 and $84 \mathrm{wt} \%$ for UF and TF, respectively. This indicates higher thermal stability for TF due to the MAPE coating. These results also indicate that the materials have good thermal stability for the range of processing conditions selected. The DTG curves show that for each material, several peaks are present and located at similar temperatures. However, their intensities and total weight loss are different. To obtain more information about the surface treatment performed, the amount of MAPE grafted on the fiber surface was determined. For this purpose, the method proposed by Chimeni et al. [30] was used. Firstly, the maximum weight loss $\Delta m$ of the MAPE (between $400{ }^{\circ} \mathrm{C}$ and $500^{\circ} \mathrm{C}$ ) can be determined with the following formula:

$$
m_{M A P E}=\Delta m_{T F}-\Delta m_{U F}
$$

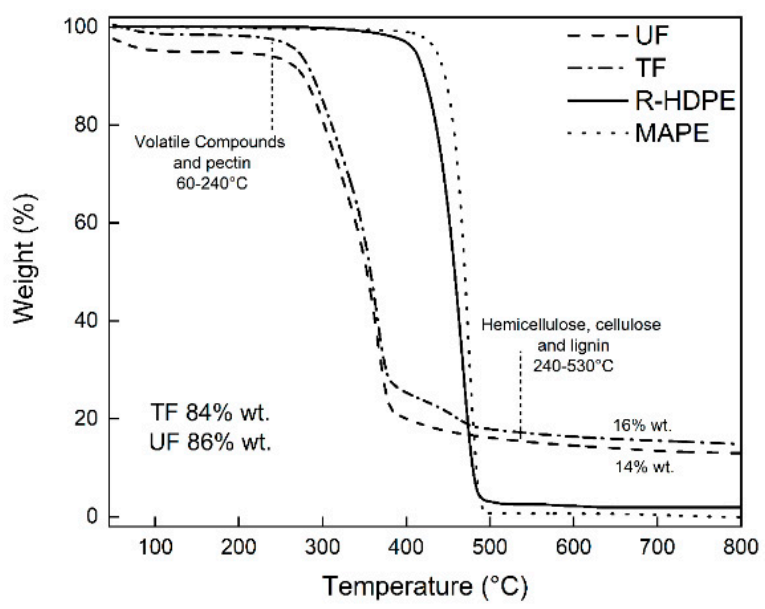

(a)

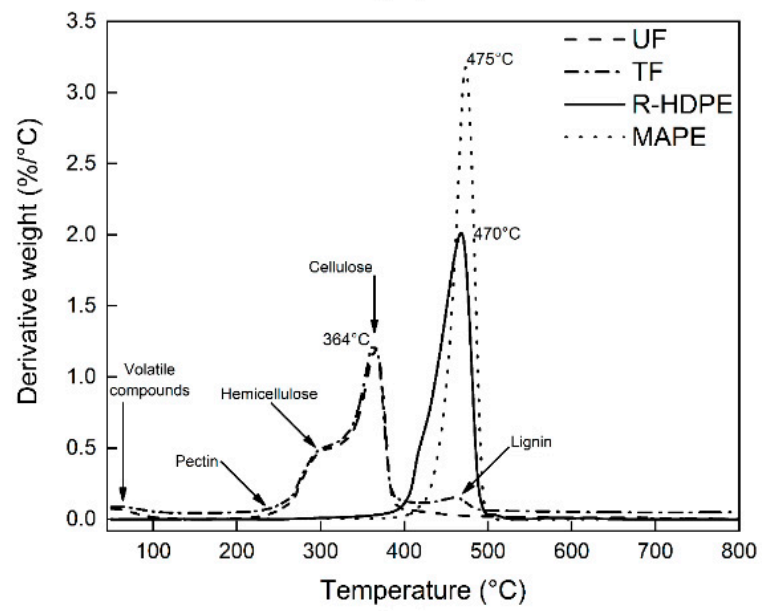

(b)

Figure 4. Thermogravimetric analysis (a) and the derivative (b) curves of the neat materials: maleated polyethylene (MAPE), recycled high density polyethylene (R-HDPE), as well as untreated (UF) and treated (TF) maple fibers under a nitrogen atmosphere. 
With $\Delta m=\left(m_{2}-m_{1}\right)$, where $m_{1}$ and $m_{2}$ are the mass of maple fiber (TF or UF) at $400{ }^{\circ} \mathrm{C}$ and $500{ }^{\circ} \mathrm{C}$, respectively (Figure 4 ). Then, the amount MAPE grafted $\left(T_{G R}\right)$ is determined as:

$$
T_{G R}=\left(m_{M A P E} * 100\right) / m_{1}
$$

where $T_{G R}=19 \%$. Finally, according to the literature [17,34], Figure 4 shows that it is possible to identify the fibers' main components.

\subsection{Morphology}

Morphological analysis is presented in Figures 5-8. Figure 5 shows the micrographs of the surface of untreated (UF) and treated (TF) fibers. The micrographs show significant differences between treated (Figure 5a) and untreated (Figure $5 b$ ) fibers. It can be observed that the surface of UF is rougher with sharp edges as compared to the surface of the treated fiber, which has a more uniform/smooth texture due to a thin MAPE layer. These observations confirm that the fiber surface treatment was successful.
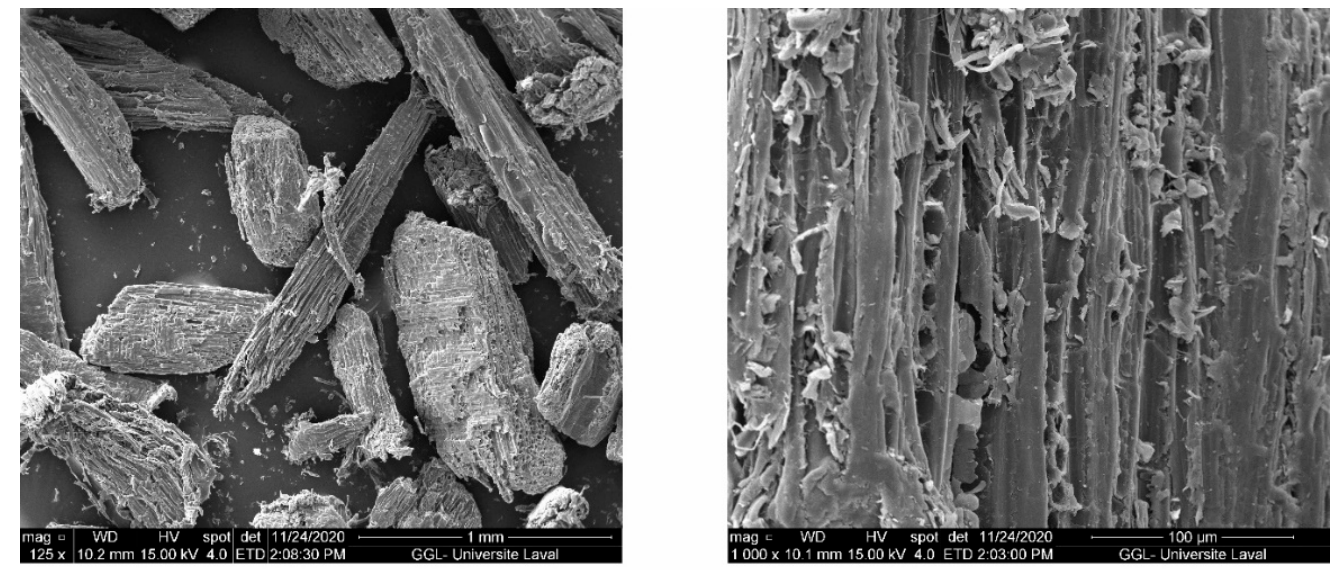

(a)
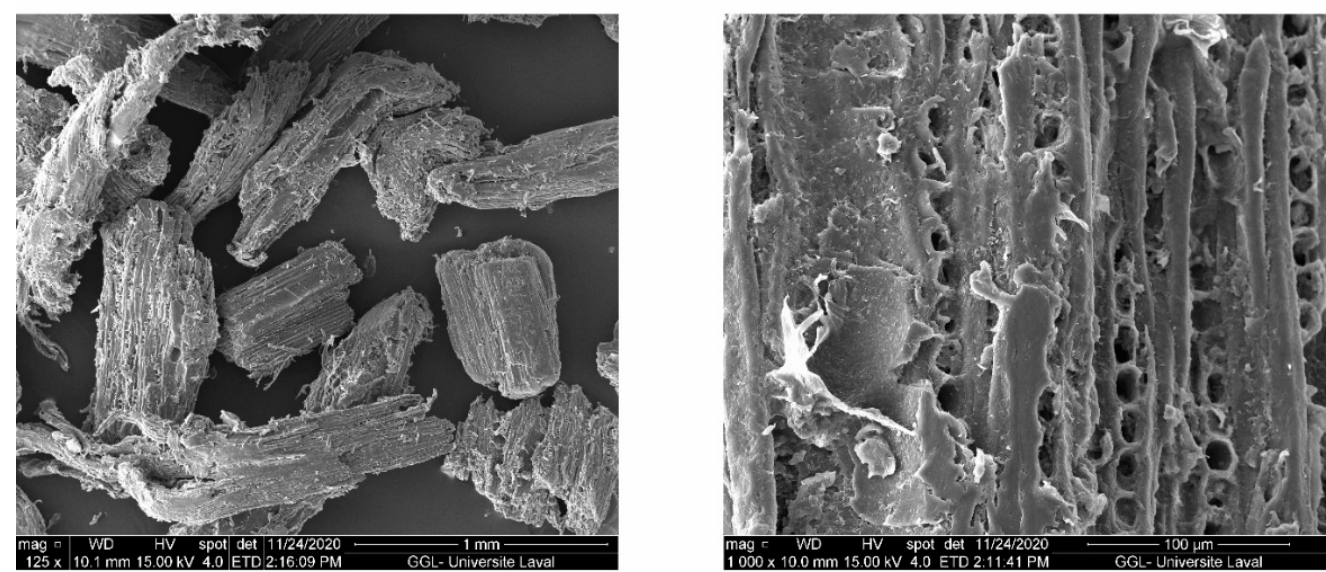

(b)

Figure 5. Surface of the maple fibers at $125 \times$ (left) and $1000 \times$ (right) magnification: (a) untreated and $(\mathbf{b})$ treated. 


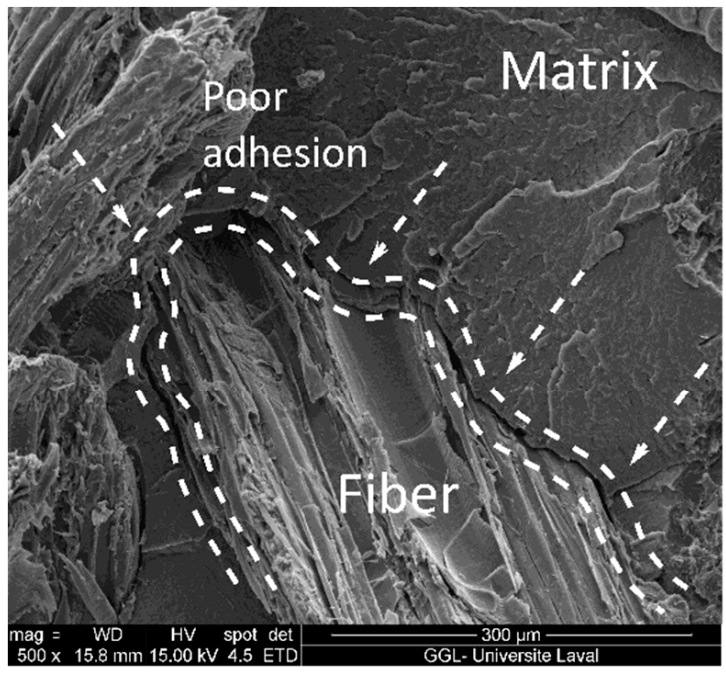

(a)

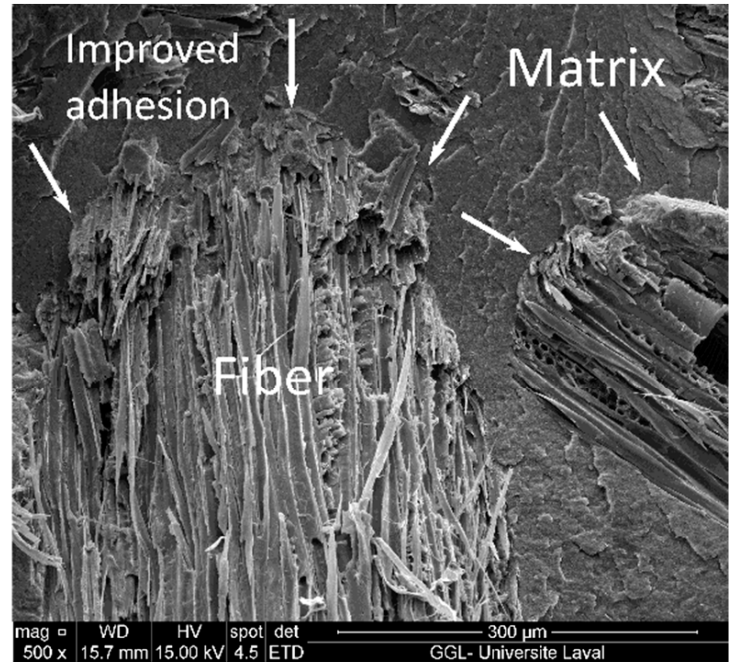

(b)

Figure 6. Interfacial state difference between recycled high density polyethylene and maple fiber composites (30 wt $\%$ ) for (a) untreated and (b) treated fibers.
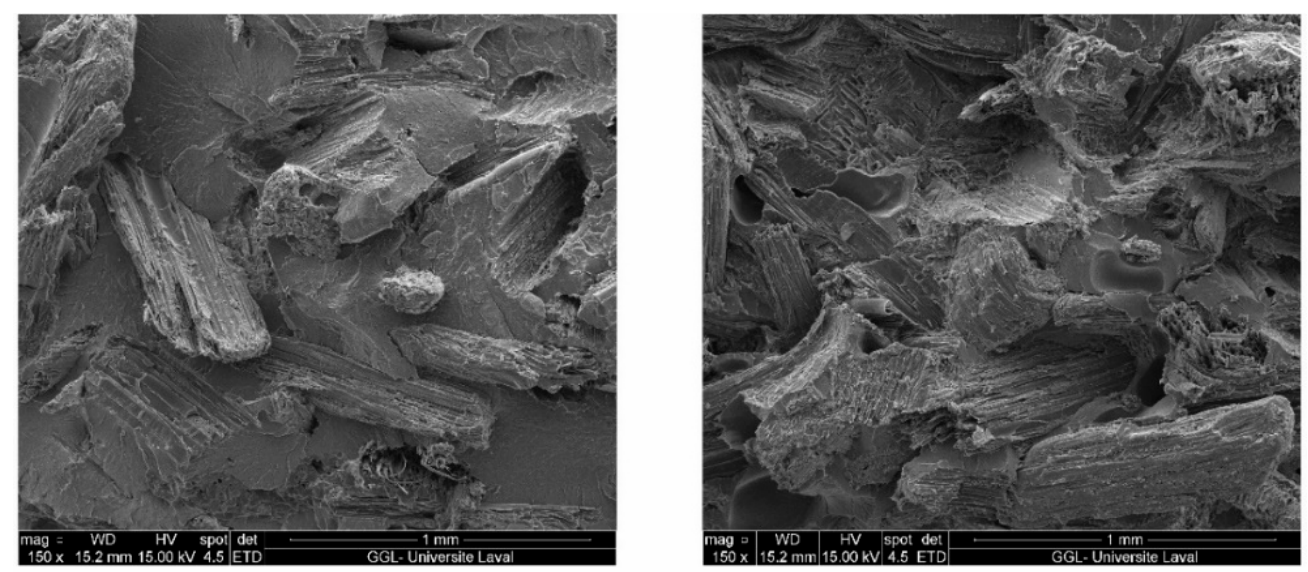

(a)
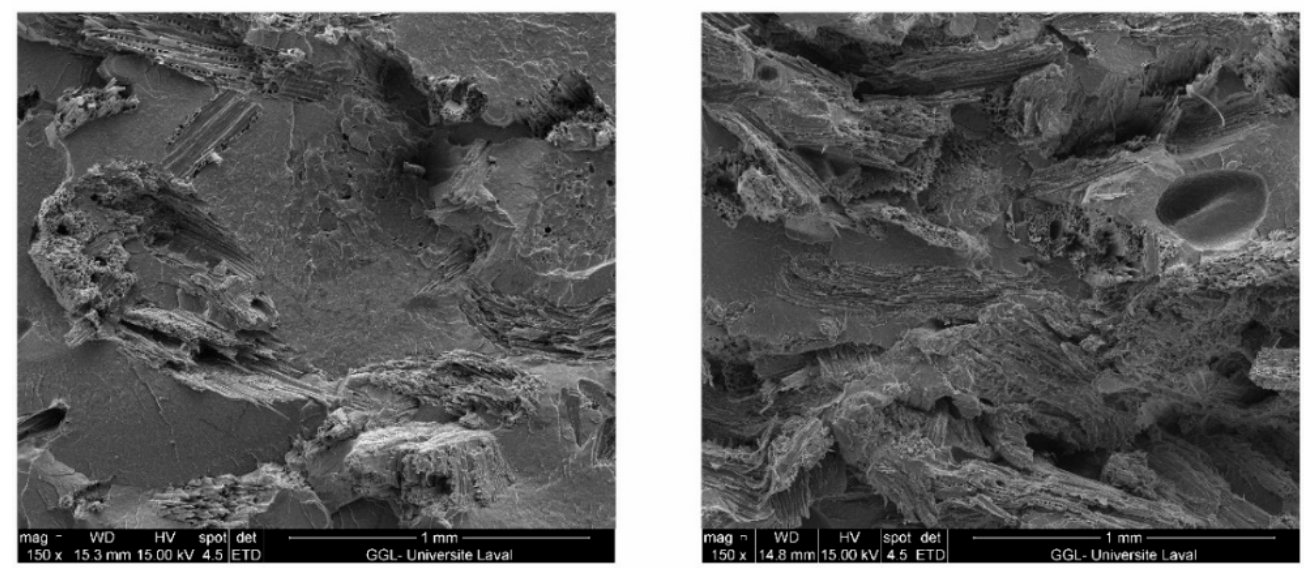

(b)

Figure 7. Scanning electron microscope (SEM) images of the recycled high-density polyethylene and maple fiber composite cross-sections with $30 \mathrm{wt} \%$ (left column) and $60 \mathrm{wt} \%$ (right column) for (a) untreated and (b) treated fibers. 


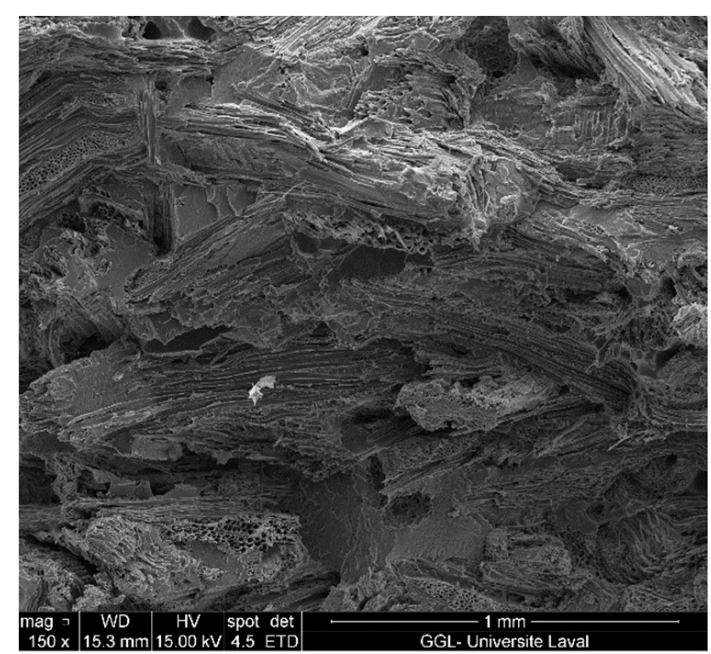

(a)

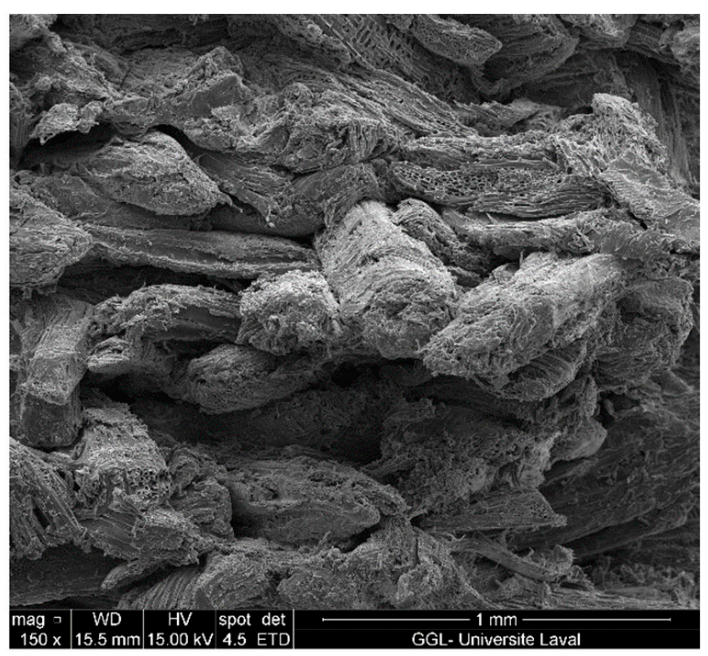

(b)

Figure 8. Scanning electron microscope (SEM) images of the treated fiber composite cross-sections with different fiber content: (a) $75 \mathrm{wt} \%$ and (b) $100 \mathrm{wt} \%$.

The interfacial adhesion between the fiber and the matrix plays an important role in determining the mechanical properties of composites. This means that improved interfacial adhesion between both component leads to improved properties. Figure 6 shows the interfacial interaction between R-HDPE and untreated (a) and treated (b) maple fibers. The effect of the coupling agent can be observed since TC fibers are well-embedded inside the matrix, while voids and defects around them are not observed. This is not the case for UC, showing clear evidence of poor interfacial adhesion that leads to voids or defects, which are the main factors that decrease the mechanical properties of the composites.

Due to the processing method used, it is possible to observe that the fibers are welldistributed, with a random orientation; Figure 7 shows typical micrographs for UC and TC samples. For UC, a lower interfacial adhesion between both components is observed and the number of defects increases with increasing fiber content [17]. In addition, fiber agglomeration can be seen as well as the presence of holes associated with fiber pull-out. These defects are known to have a negative effect on the mechanical properties (especially strength and impact) of the composites [35]. On the contrary, a more homogenous structure can be seen in TC, which indicates an improved adhesion between the materials. The fiber surface with MAPE improved adhesion/dispersion, which led to a significant decrease in the number of voids and pull-outs. There was also less fiber agglomeration.

It is important to highlight that it was not possible to obtain composites above $70 \mathrm{wt} \%$ with UF, while samples of up to $75 \mathrm{wt} \%$ was possible for TF (Figure 8a). This confirms that the surface treatment not only improves dispersion and adhesion between the maple fibers and R-HDPE, but also provides the possibility of using much higher fiber contents, improving not only the physico-chemical properties, but also other properties such as sustainability and cost. Additionally, it was possible to obtain a sample based on treated fibers alone (Figure $8 b$ ), which is a clear indication of the efficiency of the treatment performed.

Figure 9 presents the EDS spectra of UF and TF, showing again that the treatment performed on the fibers' surface was successful. In particular, the $\mathrm{C} / \mathrm{O}$ ratio on the surface of treated fibers is much higher (2.35) as compared to the value (1.59) for untreated fibers; this is due to the presence of hydrocarbon chains of MAPE covering the hydroxyl groups of cellulose. 


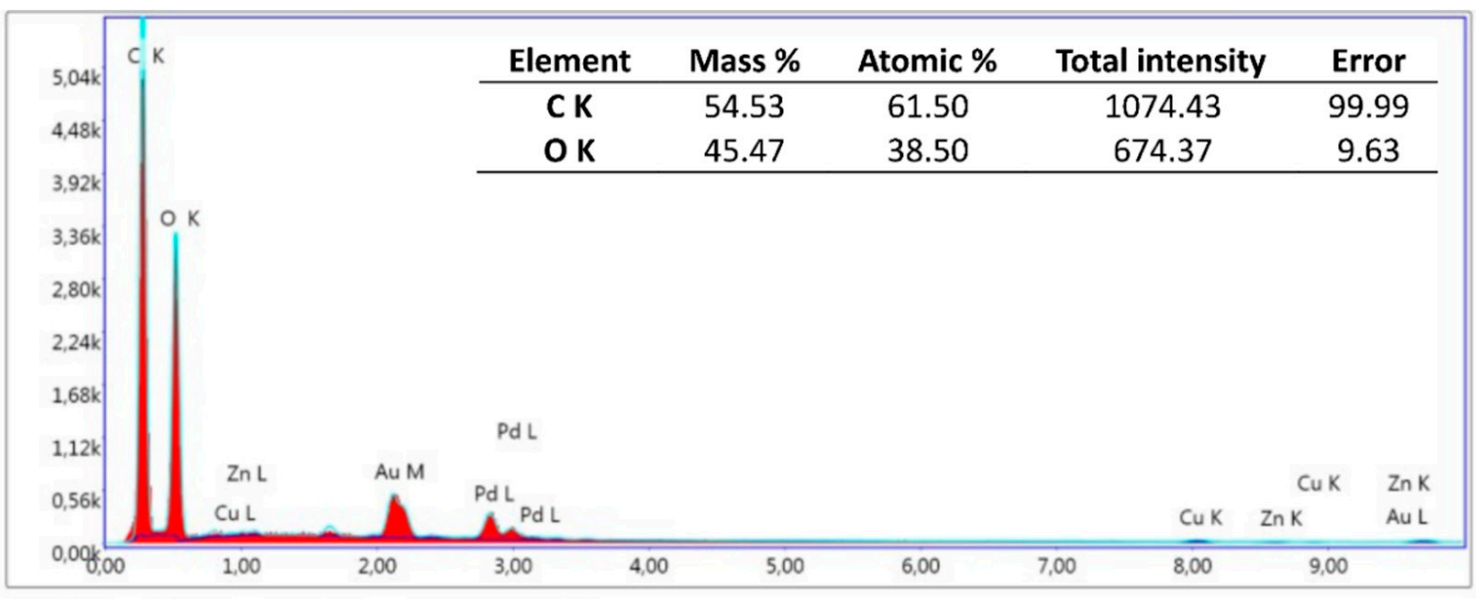

(a)

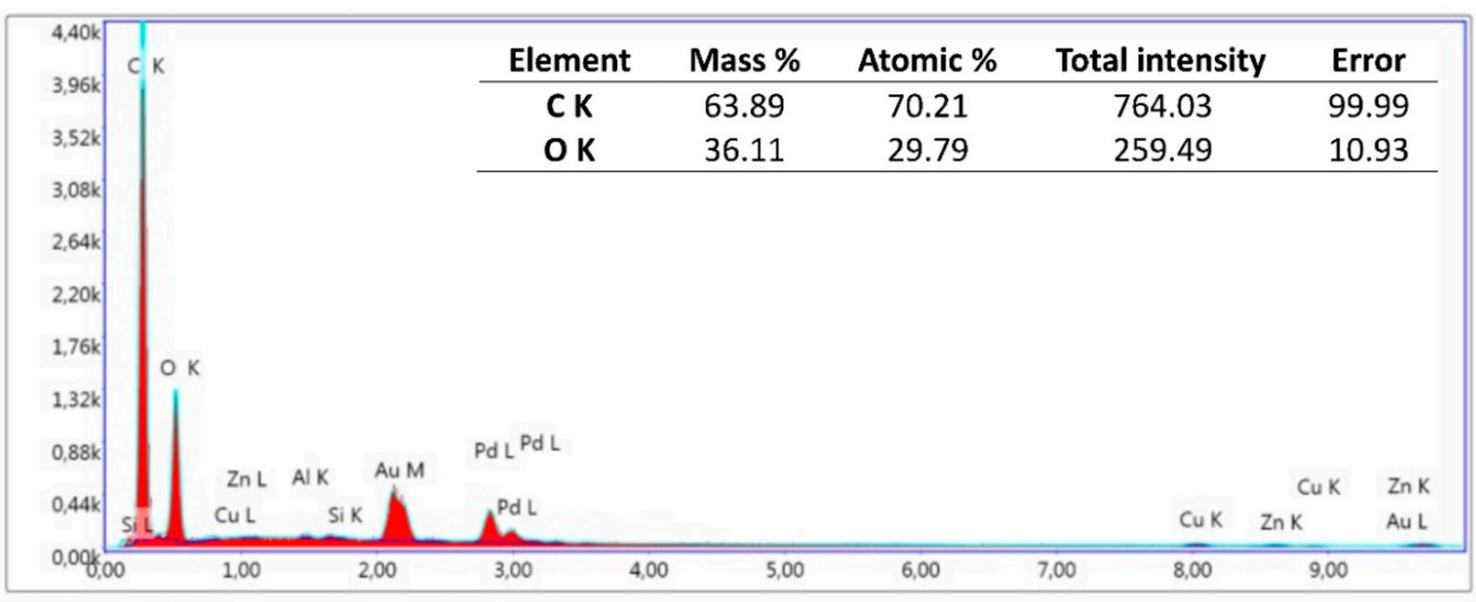

(b)

Figure 9. Energy dispersive spectroscopy (EDS) spectra for the maple fibers: (a) untreated and (b) treated.

\subsection{Density/Hardness}

The density of the samples produced is summarized in Table 1. As expected, composite density increased with fiber content. This is mainly related to the fiber density $\left(1420 \mathrm{~kg} / \mathrm{m}^{3}\right.$ for UF and $1340 \mathrm{~kg} / \mathrm{m}^{3}$ for TF) being much higher than the neat matrix $\left(943 \mathrm{~kg} / \mathrm{m}^{3}\right)$. Due to the surface treatment performed, the composites based on treated fiber (TC) have lower density than those based on untreated ones (UC), which confirms once again that the structure of the fiber was modified, as seen in Figure 3. Since the properties of the fibers were modified, which increased (cellulose, lignin) or decreased (extractives, pectin, polysaccharides, waxes) the content of the main components of the fiber (Figure 3), this also decreased the apparent fiber density. In addition, the presence of a layer of a less dense polymer $\left(\mathrm{MAPE}=923 \mathrm{~kg} / \mathrm{m}^{3}\right.$ ) on the fiber surface also contributed to density reduction [26]. 
Table 1. Density of the samples produced $\left(+/-1 \mathrm{~kg} / \mathrm{m}^{3}\right)$.

\begin{tabular}{ccc}
\hline Fiber Content $\mathbf{( w t} \%)$ & Untreated & Treated \\
\hline 0 & 1009 & 946 \\
15 & 1033 & 969 \\
30 & 1092 & 990 \\
45 & 1146 & 1024 \\
60 & 1168 & 1129 \\
70 & - & 1147 \\
75 & & 1158 \\
\hline
\end{tabular}

Neat material density: Recycled high density polyethylene $=943 \mathrm{~kg} / \mathrm{m}^{3}$, untreated $=1420 \mathrm{~kg} / \mathrm{m}^{3}$, and treated $=$ $1340 \mathrm{~kg} / \mathrm{m}^{3}$ maple fibers.

Figure 10 presents the hardness values (Shore D) for the composites. Due to the reinforcing effect provided by the fibers (indentation resistance), the hardness tends to increase with fiber content [12]. The results showed a slight increase in Shore D hardness in UC (67.2 at $15 \mathrm{wt} \%$ ) with respect to the neat R-HDPE (65.4) and a maximum at $45 \mathrm{wt} \%$ fiber content (69.6). Similarly, in the case of TC at $45 \mathrm{wt} \%$, the maximum hardness value (70.3) was observed with respect to R-HDPE (5 Shore D units). Independently of the fiber content, an increase in hardness was observed in all TC with respect to UC, with increases of up to $10 \%$. This is mainly related to the surface treatment performed, which improved the fiber-matrix interactions by reducing porosity, thus leading to fewer defects and voids in the composites [9].

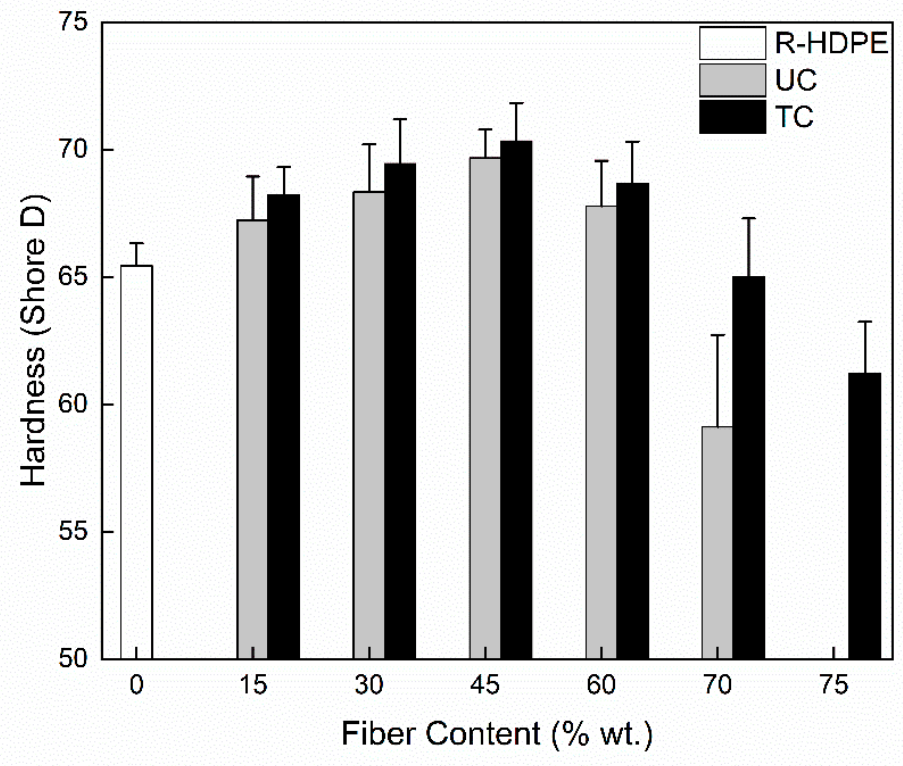

Figure 10. Hardness (Shore D) of the recycled high-density polyethylene (R-HDPE), untreated (UC) and treated (TC) composites as a function of fiber content.

\subsection{Mechanical Properties}

\subsubsection{Tensile}

Tensile properties are presented in Figures 11 and 12. Figure 11 shows that the fiber content in UC increases the tensile modulus by $5 \%$ at $30 \mathrm{wt} \%$ fiber content as compared to the neat R-HDPE. However, the tensile strength (Figure 12a) decreased from 22 to $2 \mathrm{MPa}$, mainly due to poor fiber-matrix interfacial adhesion (Figures 6 and 7). Furthermore, the literature reports that the stress distribution in composites is concentrated around the fibers $[14,16]$. Consequently, if the interactions between the fiber and the matrix are weak (presence of voids and exposed fibers), there is discontinuity (Figure 6a) and poor stress transfer. On the other hand, TCs have higher tensile modulus and tensile strength as 
compared to neat R-HDPE. The optimal values are observed at $45 \mathrm{wt} \%$ of fiber content for tensile modulus (23\%) and tensile strength (26\%). This indicates that the surface treatment improves interfacial stress transfer producing better interactions between both phases (Figure 6b) and improving all the properties, especially at a higher fiber content (above $45 \mathrm{wt} \%)$. Similar trends have been reported in the literature [15,19,32]. For the elongation at break (Figure 11), similar trends for UC and TC were observed: a decrease from $34 \%$ to $10 \%$ for the former, and from $39 \%$ to $8 \%$ for the latter. But TC values are always slightly higher for UC using the same fiber content. This loss of elongation is mainly due to the low elasticity of the fibers imposing some limitations on the mobility of the matrix chains [36].

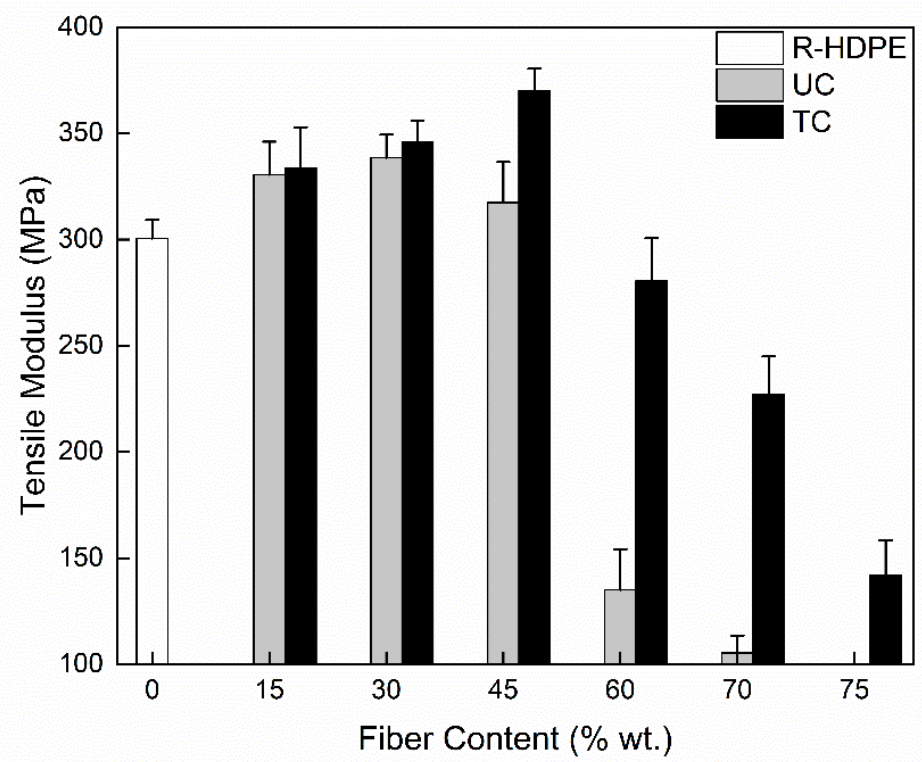

Figure 11. Tensile modulus of the recycled high-density polyethylene (R-HDPE), untreated (UC) and treated (TC) composites as a function of fiber content.

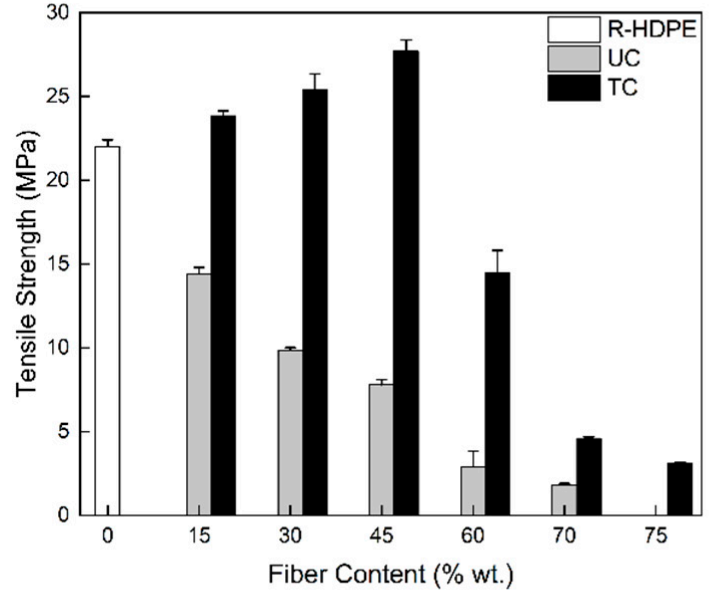

(a)

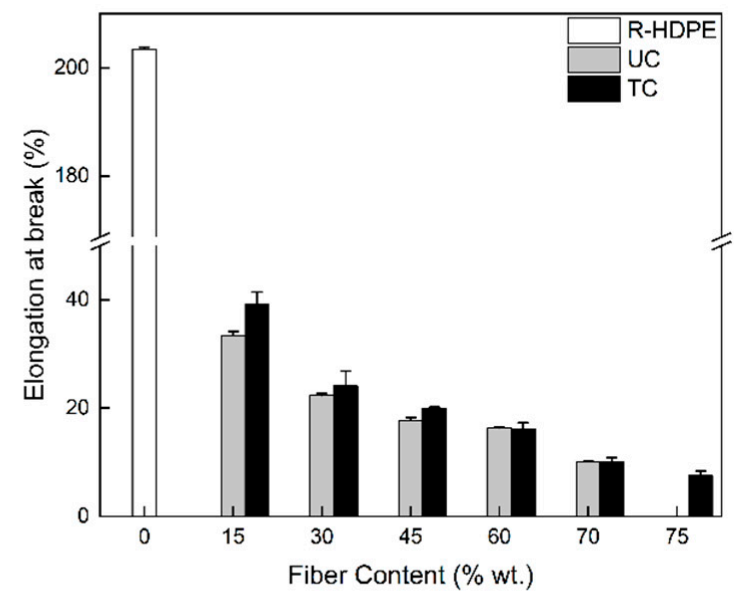

(b)

Figure 12. Tensile strength (a) and elongation at break (b) of the recycled high-density polyethylene (R-HDPE), untreated (UC) and treated (TC) composites as a function of fiber content.

\subsubsection{Flexural}

Flexural modulus and flexural strength are reported in Figure 13. For both properties, a trend similar to that of the tensile properties is observed: the flexural modulus 
(Figure 13a) increases with fiber content until an optimal value. The improvement in the flexural properties of composites can be attributed to the high modulus and strength of lignocellulosic fibers. Again, the modulus and strength are higher for TC than for UC. This is due to better interfacial adhesion between the matrix and the fibers, leading to a more uniform distribution of the applied stress, which requires more energy for fiber pull-out since they are better embedded in the matrix [37]. This significantly improved the flexural properties as the flexural modulus reached a maximum value (19\%) at $30 \mathrm{wt} \%$ UF compared to neat R-HDPE. Conversely, an improvement of up to $54 \%$ was achieved at $45 \mathrm{wt} \%$ TF. Favaro et al. [14] reported similar results for recycled HDPE composites reinforced with sisal fiber and produced by injection molding.

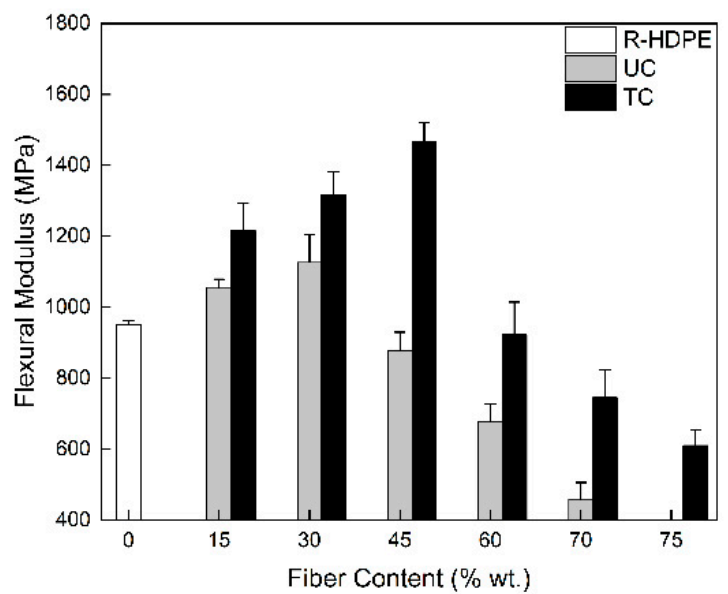

(a)

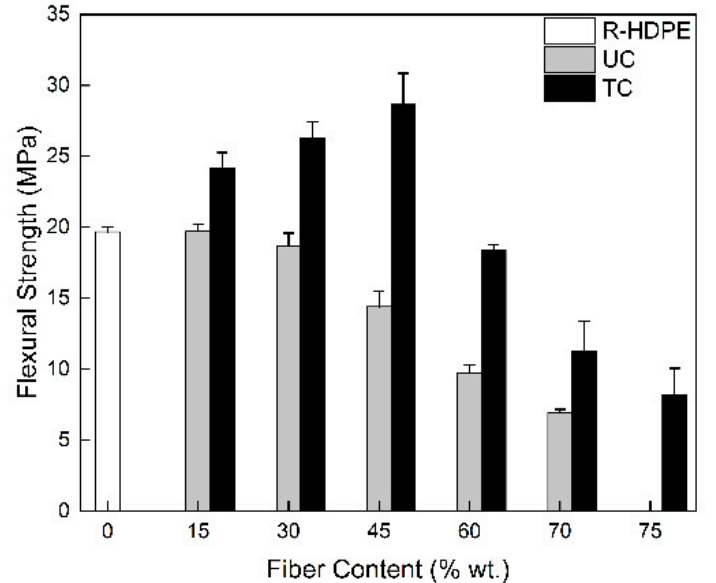

(b)

Figure 13. Flexural modulus (a) and flexural strength (b) for recycled high-density polyethylene (R-HDPE), untreated (UC) and treated (TC) composites as a function of fiber content.

The flexural strength (Figure 13b) in UC decreased as the fiber content increased, which is again an indication of poor interfacial adhesion. On the contrary, an improvement of up to $46 \%$ was obtained for $45 \mathrm{wt} \% \mathrm{TF}$ as compared to neat R-HDPE. Similar results were reported by Cisneros et al. [26] in composites based on virgin LLDPE/agave fibers, as well as by Sood et al. [16] for R-HDPE/sisal fibers.

\subsubsection{Charpy impact}

Charpy impact strength results are shown in Figure 14. In UC, the impact resistance slightly increased (18\% and $9 \%$ ) with $15 \%$ and $30 \%$ of fiber, respectively, as compared to the neat R-HDPE, but the resistance decreased with higher fiber content. As demonstrated in Figures $6 a$ and $7 \mathrm{a}$, the number of defects increases with fiber concentration, which leads to poor interfacial interaction between the fiber and matrix, thus creating poor stress transfer between both phases and resulting in poor interfacial strength, increased fiber pull-out, and increased stress concentration points for easy crack initiation and growth. Another factor that decreases the impact strength with higher fiber content is the higher number of fiber-fiber contact, which has a direct effect on failure. But this effect is less important in treated fibers because a large amount of energy is consumed/dissipated in separating the fibers from the matrix. For TC, the higher the fiber content, the higher the strength as compared to UC due to the better distribution and adhesion of the fibers inside the matrix (Figures $6 \mathrm{~b}$ and $7 \mathrm{~b}$ ). The impact resistance increased by $23 \%, 12 \%$, and $5 \%$ with 15,30 , and $45 \mathrm{wt} \%$ of fiber, respectively, as compared to neat R-HDPE. In the same way, as in UC, the resistance tends to decrease with higher fiber content. Nevertheless, an increase of up to $87 \%$ was observed in the impact resistance of TC as compared to UC. These results are 
in agreement with Lei et al. [19] on pine fiber and bagasse composites (with and without MAPE) using R-HDPE as the matrix, as well as with Samariha et al. [38] on composites based on virgin polypropylene (PP) and bagasse flour.

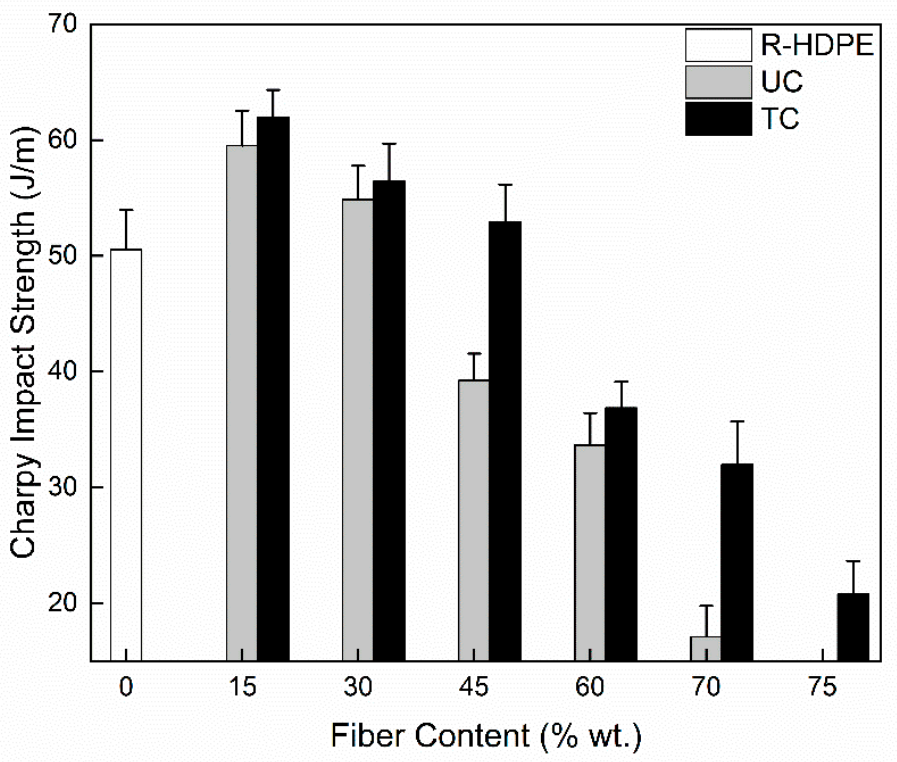

Figure 14. Charpy impact strength for recycled high-density polyethylene (R-HDPE), untreated (UC) and treated (TC) composites as a function of fiber content.

Finally, as mentioned above, it was possible to obtain samples based on $100 \%$ treated fibers. The density and hardness (shore D) for these were $1360 \mathrm{~kg} / \mathrm{m}^{3}$ and 60 , respectively. Table 2 shows the results of the mechanical properties of these samples. This is additional evidence that the treatment was effective.

Table 2. Mechanical properties of a sample based on $100 \%$ of treated fiber.

\begin{tabular}{cccccc}
\hline & Tensile & & \multicolumn{2}{c}{ Flexural } & $\begin{array}{c}\text { Charpy } \\
\text { Impact }\end{array}$ \\
\hline $\begin{array}{c}\text { Modulus } \\
(\mathbf{M P a})\end{array}$ & $\begin{array}{c}\text { Strength } \\
\mathbf{( M P a )}\end{array}$ & $\begin{array}{c}\text { Elongation } \\
\text { at Break (\%) }\end{array}$ & $\begin{array}{c}\text { Modulus } \\
\mathbf{( M P a )}\end{array}$ & $\begin{array}{c}\text { Strength } \\
\mathbf{( M P a )}\end{array}$ & $\begin{array}{c}\text { Strength } \\
\mathbf{( J / m )}\end{array}$ \\
\hline $506 \pm 26$ & $5.7 \pm 0.2$ & $1.4 \pm 0.2$ & $1168 \pm 75$ & $9.4 \pm 0.9$ & $16.8 \pm 1.5$ \\
\hline
\end{tabular}

\section{Conclusions}

In this work, composites based on recycled high-density polyethylene (R-HDPE) and maple fibers with and without surface treatment (maleated polyethylene, MAPE in solution) were prepared in a wide range of concentrations (up to $75 \mathrm{wt} \%$ ) using a simple dry-blending technique, followed by compression molding.

The FTIR and TGA analyses confirmed that the fiber surface treatment was successful and produced surface changes. This was also verified by visual observation via SEM, chemical composition via EDS, and density changes.

For the composites, the treated fibers showed a clear reduction of voids, defects, and exposed fibers improving interfacial compatibility, fiber dispersion, and fiber/matrix adhesion (interactions). This modification was shown to improve the mechanical properties in terms of tensile $(23 \%)$ and flexural $(54 \%)$ modulus, as well as the tensile $(26 \%)$ and flexural $(46 \%)$ strengths with respect to the neat R-HDPE matrix. Likewise, the impact resistance of the samples produced with treated fibers showed higher values (87\%) compared with untreated fibers.

In addition, treated fibers enabled the introduction of a much higher fiber content to produce good parts. In our case, it was possible to produce composites with up to $75 \%$ 
of treated maple fibers as compared to only $70 \%$ for the untreated fibers. Furthermore, a sample with $100 \mathrm{wt} \%$ of treated fiber was produced. Although the properties were not very high, further optimization on the treatment and processing conditions (molding) could lead to better results. This part is still under investigation.

Finally, the results obtained showed that simple methods (solution treatment, dry blending, and compression molding) can be used to produce low-cost composites based on natural fibers combined with recycled thermoplastics. These materials can be considered as good alternatives for the efficient recycling and reuse of these wastes in order to achieve sustainable products.

Author Contributions: Conceptualization, D.R.; methodology, R.C.V.F. and D.R.; formal analysis, R.C.V.F.; investigation, R.C.V.F.; resources, D.R.; data curation, R.C.V.F. and D.R.; writing-original draft preparation, R.C.V.F. and D.R.; writing - review and editing, R.C.V.F. and D.R.; supervision, D.R.; project administration, D.R.; funding acquisition, D.R. All authors have read and agreed to the published version of the manuscript.

Funding: This research received no external funding.

Acknowledgments: The authors acknowledge the technical support of the research center on advanced materials (CERMA).

Conflicts of Interest: The authors declare no conflict of interest.

\section{References}

1. Schnurr, R.E.J.; Alboiu, V.; Chaudhary, M.; Corbett, R.A.; Quanz, M.E.; Sankar, K.; Srain, H.S.; Thavarajah, V.; Xanthos, D.; Walker, T.R. Reducing marine pollution from single-use plastics (SUPs): A review. Mar. Pollut. Bull. 2018, 137, 157-171. [CrossRef]

2. Herberz, T.; Barlow, C.Y.; Finkbeiner, M. Sustainability Assessment of a Single-Use Plastics Ban. Sustainability 2020, $12,3746$. [CrossRef]

3. Gulitah, V.; Liew, K.C. Three different recycle codes of plastic/Acacia fibre composites: Physical and morphological properties. Int. J. Biobased Plast. 2019, 1, 1-7. [CrossRef]

4. Geyer, R.; Jambeck, J.R.; Law, K.L. Production, use, and fate of all plastics ever made. Sci. Adv. 2017, 3, e1700782. [CrossRef] [PubMed]

5. Singh, N.; Hui, D.; Singh, R.; Ahuja, I.P.S.; Feo, L.; Fraternali, F. Recycling of plastic solid waste: A state of art review and future applications. Compos. Part B 2017, 115, 409-422. [CrossRef]

6. Mohanty, A.K.; Vivekanandhan, S.; Pin, J.-M.; Misra, M. Composites from renewable and sustainable resources: Challenges and innovations. Science 2018, 362, 536-542. [CrossRef]

7. Garcia, J.M.; Robertson, M.L. The future of plastics recycling. Science 2017, 358, 870-872. [CrossRef]

8. Pivnenko, K.; Eriksen, M.K.; Martín-Fernández, J.A.; Eriksson, E.; Astrup, T.F. Recycling of plastic waste: Presence of phthalates in plastics from households and industry. Waste Manag. 2016, 54, 44-52. [CrossRef]

9. Valente, M.; Quitadamo, A. Polymeric matrix composites at reduced environmental impact. Polym. Eng. Sci. 2017, 57, 651-656. [CrossRef]

10. Ratanawilai, T.; Taneerat, K. Alternative polymeric matrices for wood-plastic composites: Effects on mechanical properties and resistance to natural weathering. Constr. Build. Mater. 2018, 172, 349-357. [CrossRef]

11. Liu, Y.; Li, X.; Wang, W.; Sun, Y.; Wang, H. Decorated wood fiber/high density polyethylene composites with thermoplastic film as adhesives. Int. J. Adhes. Adhes. 2019, 95, 102391. [CrossRef]

12. Koffi, A.; Koffi, D.; Toubal, L. Mechanical properties and drop-weight impact performance of injection-molded HDPE/birch fiber composites. Polym. Test. 2021, 93, 106956. [CrossRef]

13. Cisneros-López, E.O.; González-López, M.E.; Pérez-Fonseca, A.A.; González-Núñez, R.; Rodrigue, D.; Robledo-Ortíz, J.R. Effect of fiber content and surface treatment on the mechanical properties of natural fiber composites produced by rotomolding. Compos. Interfaces 2017, 24, 35-53. [CrossRef]

14. Fávaro, S.L.; Ganzerli, T.A.; de Carvalho Neto, A.G.V.; da Silva, O.R.R.F.; Radovanovic, E. Chemical, morphological and mechanical analysis of sisal fiber-reinforced recycled high-density polyethylene composites. Express Polym. Lett. 2010, 4, 465-473. [CrossRef]

15. Lu, N.; Oza, S.A. comparative study of the mechanical properties of hemp fiber with virgin and recycled high density polyethylene matrix. Compos. Part B Eng. 2013, 45, 1651-1656. [CrossRef]

16. Sood, M.; Dharmpal, D.; Gupta, V.K. Effect of Fiber Chemical Treatment on Mechanical Properties of Sisal Fiber/Recycled HDPE Composite. Mater. Today Proc. 2015, 2, 3149-3155. [CrossRef]

17. Cestari, S.P.; Mendes, L.C.; Altstädt, V.; Lopes, L.M.A. Upcycling polymers and natural fibers waste-Properties of a potential building material. Recycling 2016, 1, 205-218. [CrossRef] 
18. Taufiq, M.J.; Mansor, M.R.; Mustafa, Z. Characterisation of wood plastic composite manufactured from kenaf fibre reinforced recycled-unused plastic blend. Compos. Struct. 2018, 189, 510-515. [CrossRef]

19. Lei, Y.; Wu, Q.; Yao, F.; Xu, Y. Preparation and properties of recycled HDPE/natural fiber composites. Compos. Part. A Appl. Sci. Manuf. 2007, 38, 1664-1674. [CrossRef]

20. Cai, Z.; Al Faruque, M.A.; Kiziltas, A.; Mielewski, D.; Naebe, M. Sustainable lightweight insulation materials from textile-based waste for the automobile industry. Materials 2021, 14, 1241. [CrossRef] [PubMed]

21. Syduzzaman, M.; Al Faruque, M.A.; Bilisik, K.; Naebe, M. Plant-based natural fibre reinforced composites: A review on fabrication, properties and applications. Coatings 2020, 10, 973. [CrossRef]

22. Chowdhury, I.H.; Abdelwahab, M.A.; Misra, M.; Mohanty, A.K. Sustainable Biocomposites from Recycled Bale Wrap Plastic and Agave Fiber: Processing and Property Evaluation. ACS Omega 2021, 6, 2856-2864. [CrossRef]

23. Vázquez Fletes, R.C.; Raymond, A.; Rodrigue, D. Effect of surface modification and fiber content on the mechanical performance of compression molded polyethylene-maple composites. Polym. Compos. 2021, 42, 1977-1987. [CrossRef]

24. Siregar, J.P.; Jaafar, J.; Cionita, T.; Jie, C.C.; Bachtiar, D.; Rejab, M.R.M.; Asmara, Y.P. The Effect of Maleic Anhydride Polyethylene on Mechanical Properties of Pineapple Leaf Fibre Reinforced Polylactic Acid Composites. Int. J. Precis. Eng. Manuf. Green Technol. 2019, 6, 101-112. [CrossRef]

25. Mohammed, L.; Ansari, M.N.M.; Pua, G.; Jawaid, M.; Islam, M.S. A Review on Natural Fiber Reinforced Polymer Composite and Its Applications. Int. J. Polym. Sci. 2015, 2015, 1-15. [CrossRef]

26. Cisneros-López, E.O.; Anzaldo, J.; Fuentes-Talavera, F.J.; González-Núñez, R.; Robledo-Ortíz, J.R.; Rodrigue, D. Effect of agave fiber surface treatment on the properties of polyethylene composites produced by dry-blending and compression molding. Polym. Compos. 2017, 38, 96-104. [CrossRef]

27. Raharjo, W.W.; Soenoko, R.; Irawan, Y.S.; Suprapto, A. The Influence of Chemical Treatments on Cantala Fiber Properties and Interfacial Bonding of Cantala Fiber/Recycled High Density Polyethylene (rHDPE). J. Nat. Fibers 2018, 15, 98-111. [CrossRef]

28. Satapathy, S. Development of value-added composites from recycled high-density polyethylene, jute fiber and flyash cenospheres: Mechanical, dynamic mechanical and thermal properties. Int. J. Plast. Technol. 2018, 22, 386-405. [CrossRef]

29. Dou, Y.; Rodrigue, D. Morphological, thermal and mechanical properties of recycled HDPE foams via rotational molding. J. Cell. Plast. 2021, 0, 1-19.

30. Hanana, F.E.; Chimeni, D.Y.; Rodrigue, D. Morphology and mechanical properties of maple reinforced LLDPE produced by rotational moulding: Effect of fibre content and surface treatment. Polym. Polym. Compos. 2018, 26, 299-308. [CrossRef]

31. Parre, A.; Karthikeyan, B.; Balaji, A.; Udhayasankar, R. Investigation of chemical, thermal and morphological properties of untreated and $\mathrm{NaOH}$ treated banana fiber. Mater. Today Proc. 2020, 22, 347-352. [CrossRef]

32. Mohanty, S.; Nayak, S.K. Short bamboo fiber-reinforced HDPE composites: Influence of fiber content and modification on strength of the composite. J. Reinf. Plast. Compos. 2010, 29, 2199-2210. [CrossRef]

33. Verdague, A.; Rodrigue, D. Effect of surface treatment on the mechanical properties of wood-plastic composites produced by dry-blending. In Proceedings of the 72nd Annual Technical Conference \& Exhibition; Society of Plastics Engineers, Las Vegas, NV, USA, 28-30 April 2014; pp. 2021-2025.

34. García Hernández, Z.; Miranda Teran, Z.N.; González Morones, P.; Yañez Macías, R.; Solís Rosales, S.G.; Romero, G.Y.; SifuentesNieves, I.; Hernández-Hernández, E. Performance of nylon 6 composites reinforced with modified agave fiber: Structural, morphological, and mechanical features. J. Appl. Polym. Sci. 2021, 50857. [CrossRef]

35. Bhattacharjee, S.; Bajwa, D.S. Degradation in the mechanical and thermo-mechanical properties of natural fiber filled polymer composites due to recycling. Constr. Build. Mater. 2018, 172, 1-9. [CrossRef]

36. Kazemi, Y.; Cloutier, A.; Rodrigue, D. Mechanical and morphological properties of wood plastic composites based on municipal plastic waste. Polym. Compos. 2013, 34, 487-493. [CrossRef]

37. Ashori, A.; Nourbakhsh, A. Characteristics of wood-fiber plastic composites made of recycled materials. Waste Manag. 2009, 29, 1291-1295. [CrossRef]

38. Samariha, A.; Bastani, A.; Nemati, M.; Kiaei, M.; Nosrati, H.; Farsi, M. Investigation of the Mechanical Properties of Bagasse flour/Polypropylene composites. Mech. Compos. Mater. 2013, 49, 447-454. [CrossRef] 